\title{
A inovação de valores nos laboratórios clínicos
}

\author{
Business innovation in clinical laboratories
}

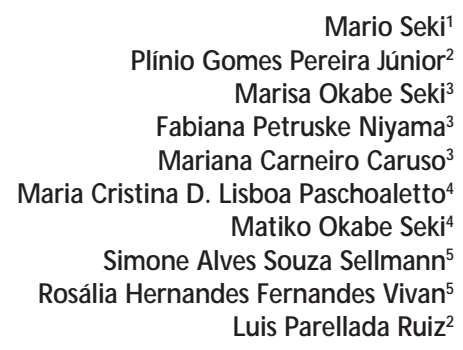

\section{unitermos}

Gestão; valor agregado; inovação de valores; mercado; laboratórios clínicos; vantagem competitiva

\section{Key words}

Management; added value; business innovation; marketing; clinical laboratories; competitive advantage

Os profissionais com atribuições de liderança em laboratórios clínicos receberam formação que os habilita para as finalidades diagnósticas, monitorização, prevenção e controle da saúde como um todo, e, de modo geral, poucos conhecimentos sobre gestão. A falta de consistência administrativa e a pouca familiaridade com textos especializados prejudicam, em muitos laboratórios de pequeno e médio portes, a transição de uma gestão amadora para uma profissional. Discussões sobre experiências mercadológicas podem minimizar essas dificuldades e, por conseguinte, contribuir para o fomento das boas práticas laboratoriais contemporâneas.

Em anos passados, os laboratórios orientavam-se, equivocadamente, pela perspectiva de dentro (empresa) para fora (mercado). Para diferenciar-se, os prestadores de serviços concentravam os seus esforços na oferta de serviços (exames) realizados com exclusividade ou em melhores condições técnicas que a concorrência. Estes procedimentos requeriam, por vezes, consultas a professores e/ou participação em cursos nos grandes centros médicos do país, tantos eram os detalhes. $\mathrm{O}$ reflexo dessas tendências está registrado nos congressos da especialidade e na então Revista Brasileira de Patologia Clínica, precursora do Jornal Brasileiro de Patologia e Medicina Laboratorial, que destinaram significativos espaços para a disseminação de informações técnicas.
Progressivamente, os mercados tradicionais deste segmento profissional foram substituídos por um ambiente empresarial permeado pelas transformações nas áreas sociais, políticas, econômicas e tecnológicas. A ruptura dos laboratórios com o modelo cartorial do sistema público de saúde, após desgastantes pleitos vãos para melhorar a tabela de honorários, é o registro mais eloqüente dessas mudanças. Ao abandonar o seu principal provedor de serviços, os laboratórios clínicos mantidos em regime de gestão familiar passaram a enfrentar as difíceis leis do livre mercado.

Os profissionais absorveram favoravelmente as influências adicionais que permitiram ampliar e diversificar o painel de analitos colocados à disposição da clientela, inclusive os de alta complexidade, como biologia molecular. Os principais fatores que contribuíram para este estágio podem ser destacados: 1) a disseminação dos kits diagnósticos industrializados, que tornou acessíveis complicadas técnicas analíticas; 2 ) os laboratórios de apoio que intensificaram sua presença graças às melhorias dos meios de transporte e comunicação, oferecendo serviços com honorários competitivos; 3 ) as facilidades de acesso aos auto-analisadores mediante comodatos, que dispensam substancial imobilização de ativos.

As conseqüências destes fenômenos mercadológicos repercutiram na equiparação dos laboratórios na
1. Médico patologista clínico do Labmed/Labimagem - Diagnóstico Avançado em Medicina (LondrinaPR) e do Laboratório Dr. Joelson (Assis-SP); aluno do Programa de Pós-Graduação, Mestrado em Medicina, pela Universidade

Estadual de Londrina-PR. 2. Médico patologista clínico do Labmed/Labimagem - Diagnóstico Avançado em Medicina (Londrina-PR).

3. Estudante de Medicina. 4. Farmacêutica bioquímica do Laboratório Dr. Joelson (Assis-SP). 5. Farmacêutica bioquímica do Labmed/Labimagem - Diagnóstico Avançado em Medicina (Londrina-PR). 
capacidade de atender os mais diversos analitos e, perversamente, no achatamento dos honorários profissionais praticados pelos maiores compradores de serviços, que passaram a tratar os exames como commodities.

Mudança mais significativa foi observada no comportamento dos clientes, que começaram a fazer prevalecer seu direito de escolha para os serviços de saúde. Mais exigente, o perfil da clientela passou a valorizar o atendimento prestado em telefonia, recepção, coleta e pós-ven$\mathrm{da}$, tanto quanto a confiança que os médicos depositavam nos laboratórios de sua preferência.

A dinâmica da nova realidade despertou os profissionais para as técnicas mercadológicas nas práticas laboratoriais, orientadas numa perspectiva de fora para dentro. Para atender as percepções e expectativas dos clientes, foi preciso agregar valores aos serviços para conquistar os clientes e torná-los leais. Desta forma, os valores agregados passaram a ser considerados um importante indicador de participação de mercado, pois podem ser convertidos em poderosa vantagem competitiva. Conceitualmente, a vantagem competitiva que promove benefícios de custos ou de qualidade ao laboratório em comparação com os concorrentes é o acesso diferenciado a recursos capazes de impulsionar os objetivos de longo prazo, como lucratividade e crescimento.

O valor agregado considerado superior, que permaneceu imutável no decorrer do tempo, e agora consolidado, é a atuação do médico patologista clínico como consultor. Na condição de especialista em medicina laboratorial, este profissional é capaz de traduzir para linguagem clínica os resultados dos exames, assim como fornecer informações adicionais sobre metodologias complementares ou alternativas. Em centros médicos universitários, além de residência médica, esta função pode requerer conhecimentos sobre metodologia em pesquisa científica, disponíveis nos cursos de pós-graduação, em níveis de mestrado e/ou doutorado.

Para corresponder às expectativas dos clientes em relação aos serviços prestados, é indispensável inovar valores que possam influir nas suas decisões de escolha. Cuidados prévios devem ser adotados para eliminar a indesejável política de restrições, resquício de um passado de atendimento aos usuários pouco exigentes. É preciso entender que a inovação pode surgir no processo, na maneira de abordar o mercado, na gestão, e não apenas na oferta de serviços (exames). A inovação de valor é um processo criativo que se opõe à lógica convencional e procura concentrar-se nos elementos comuns das características mais valorizadas, e não nas diferenças entre os clientes.

Valores adotados na rotina dos laboratórios, como coleta domiciliar, fornecimento de lanches, participação nos Programas de Excelência para Laboratórios Médicos (Pelm) e certificação em Sistemas da Qualidade (ISO), estão sendo, imperceptivelmente, incorporados como requisitos essenciais nos laboratórios de nível. Portanto não podem ser tratados atualmente como valores superiores e, tampouco, como inovadores.

A percepção de qualidade por parte dos clientes está cada vez mais atenta ao local de atendimento. Assim, cuidados devem ser dispensados para a conservação das instalações físicas, que podem incluir reforma dos ambientes da recepção, das salas de espera, da copa/cafeteria, das coletas especializadas (infantil ou provas funcionais), dos estacionamentos e, eventualmente, dos espaços para divulgação de artistas regionais. A ampliação do espaço físico pode ser destinada aos serviços de imagem, com finalidade de oferecer comodidade para os clientes realizarem diferentes exames num único local. Outros investimentos imobiliários podem incluir áreas para hospital-dia ou até mesmo instituições de alta complexidade.

O aumento da escala torna acessível o uso de autoanalisadores, uma importante inovação tecnológica que também aumenta a produtividade. Em algumas regiões do país já se observam agrupamentos de laboratórios constituindo uma única central de exames para atingir escala e, assim, obter melhor relação custo/benefício dos equipamentos. As maiores dificuldades para viabilizar as centrais de processamento de exames estão nas estratégias regionais, nos relacionamentos profissionais e nas questões de logística.

Entretanto, a equivocada procura da escala como um fim e não como um meio, comum em muitos mercados predatórios, pode exercer efeito deletério sobre a lucratividade (receitas sobre vendas). Ao contrário, para obter maior renda líquida, é preciso dispensar maior atenção à economia de mercado do que à economia de escala.

Focos estratégicos revelam a capacidade de o laboratório concentrar mais poder nos mercados escolhidos do que qualquer outro concorrente, e, assim, inovar os valores agregados. A segmentação do mercado define o foco de sua atuação e permite isolar um conjunto razoavelmente homogêneo de clientes que possam ser atendidos com 
melhor produtividade sem colocar em risco sua satisfação. Em algumas circunstâncias, é preciso decidir entre diferentes tipos de clientela: ambulatorial ou hospitalar; sistema público ou privado de saúde e, neste último, muitas vezes torna-se necessário optar entre convênios ou cooperativas médicas. $\mathrm{O}$ foco também deve ser definido para os profissionais responsáveis pelos laboratórios, pois atuação em empresas diferentes ou concorrentes, assim como prática de atividades paralelas, pode confundir a clientela médica.

Métodos inovadores, como gerenciamento de relacionamentos, podem diminuir a distância entre clientes e profissionais e, assim, amenizar impactos negativos das excessivas - embora inevitáveis - tecnicalidade e burocracia administrativa. Um relacionamento mais humano pode ser implementado através de informações extraídas em pesquisas de mercado, formatadas em um banco de dados atualizado. Hoje, mais do que nunca, é preciso saber perscrutar, antecipar expectativas e relacionar-se com os clientes para conquistar sua lealdade.

Como se observa, a cultura de inovação dos valores deve concentrar-se nos recursos humanos, incluindo processos de seleção e recrutamento, treinamentos periódicos da equipe e métodos adequados de avaliação. Os colaboradores são capazes de fornecer subsídios para melhorias contínuas dos processos, principalmente os que estão vinculados ao atendimento dos clientes. Programas de natureza cultural, social, esportiva ou lúdica promovem maior comprometimento da equipe com a empresa e estimulam criatividade voltada para a inovação. A integração entre diferentes profissionais, universitários e estagiários pode incluir incentivos à iniciação científica para identificar aqueles capazes de gerar valores sob forma de publicações.

Os mesmos cuidados devem ser tomados nas fases de sucessão ou admissão no corpo clínico de novos profissionais especializados, que podem proporcionar excelentes oportunidades para inovações nos diferentes processos.
A responsabilidade social dos profissionais dos laboratórios na comunidade é um valor que encontra receptividade, melhorando a imagem dos serviços ou de seus profissionais. Participações em atividades voltadas para problemas ambientais, sociais e assistenciais às minorias menos favorecidas podem ser efetivadas nos clubes de serviços, instituições classistas ou assistenciais.

Uma outra questão mercadológica que atualmente provoca inquietação em diversos centros médicos está relacionada aos episódios de incorporação, fusão e capitalização de laboratórios que consolidaram as primeiras corporações da área no país. A velocidade da expansão das corporações nas principais capitais, em busca de novos espaços para seu crescimento, operando muitas de suas unidades como megacomplexos de diagnóstico médico, indica que as preocupações são perfeitamente justificadas.

Diante do contexto atual e das difíceis perspectivas futuras, os laboratórios de pequeno e médio portes devem assumir gestão moderna voltada ao mercado. Para oferecer valores superiores aos clientes, que possam traduzir-se em vantagens competitivas, a equipe precisa concentrar-se no preparo científico e técnico, associado a um suporte tecnológico adequado para atender às necessidades da classe médica; às percepções dos clientes cada vez mais exigentes no atendimento e preocupados com a prevenção de erros e dos convênios atentos ao crescimento dos custos da assistência médica.

As oportunidades de inovação de valores nas rotinas de laboratórios de portes pequeno e médio não se esgotam com as experiências discutidas na presente exposição. Cada serviço necessita identificar, no seu mercado, os valores que a clientela considerará superiores em relação à concorrência. A diferença entre sucesso e insucesso para enfrentar os novos tempos está na capacidade permanente de os laboratórios inovarem os valores que satisfaçam a qualidade percebida pelo cliente.

\section{Referências}

1. A ndrio lo, A. N ovas competências do patolo gista clínico. J. Bras. Patol., 36(2): 103-5, 2000.

2. Ferraz, E. 0 motor da inovação. Exame, 776(20): 46-55, 2002.

3. Harvard Business Review Book. Atuação espetacular. 1. ed. Rio de Janeiro: C ampus, 1997.

4. Harvard Business Review. Exame, 776(20): 56-64, 2002.
5. Kim,W .C .\& Mauborgne, R. Inovação de valor. A lógica estratégica do alto crescimento. In: Harvard Business Review. Estratégias para o crescimento. 1. ed. Rio de Janeiro: C ampus. 2000. p. 31-56.

6. Lima, S.A. Cliente: eu não vivo sem você. 9. ed. Bahia: Casa da Q ualidade, 1995. 
7. Murphy, D. MBA Compacto - Marketing. 1. ed. Rio de Janeiro: C ampus, 2000.

8. 0 liveira, U.M.G estão do laboratório sob a ló gica de processos de produção e seus controles. J. Bras. Patol., 36(3): 174-5, 2000.

9. 0 liveira, U.M. A residência médica em patologia clínica: sugestões para uma mudança necessária. J. Bras. Patol., 36(3): 176-7, 2000.

10. Stalk Jr., G .; Pecaut, D.K. \& Burnett, B. Eliminando as restrições, desencadeando o crescimento. In:Harvard Business Review.
Estratégias para o crescimento. 1.ed. Rio de Janeiro: Campus. 2000. p. 9-30.

11. Seki, M. et al. Repercussão da implantação do ISO 9002 em laboratório clínico na participação do mercado e nos custos com pessoal. J. Bras. Patol., 37(3): 177-80, 2001.

12. Seki, M.; Seki, M .O .S. \& Pereira Jr., P.G. Contribuição para discussão segmentada sobre mercado de trabalho e perspectivas profissionais em Patologia Clínica. J. Bras. Patol., 38(3): 205-6, 2002. 